publish an account of his researches on cancer, in regard to which, as far as they have been made known, we have done our best to keep our readers informed. It is noteworthy that the lay press has from the first been better informed than the medical journals as to the progress of M. Doyen's researches. We are not surprised, therefore, that our popular contemporary should be privileged to publish what purports to be the concluding passage of the work which it announces. It runs as follows:

It must not be believed that my cancer treatment can cure patients who have but a few more days to live, and whose vital organs have been almost entirely destroyed by the ravages of generalization. It should be applied to patients whose powers of resistance are still sufficient to enable them to struggle against the progress of the malady.

I recommend an operation in all cases wherein it is feasible without danger to the patient, as it is the quickest means of ridding the organism of cancerous growths of a certain size. But it is necessary to bear in mind the danger of reinoculation, which so often occurs in the wound of an operation for cancer. This reinoculation seems to be obviated by anticancerous vaccination. I consider, therefore, that no surgical operation for cancer-even for a cancer that is superficial and easily operable-should be performed before the patient has undergone several anticancerous injections.

In cases that are absolutely inoperable the treatment presents no disadvantages. It cannot aggravate the patient's condition; consequently, it should be tried, though it may be abandoned at the end of five or six weeks if the disease is so far advanced that no other resource remains.

According to the same authority, Dr. Doyen adds that in 50 per cent. of cancerous cases the patients can be benefited by the serum treatment, and that in 25 per cent. of the cases the results obtained are equivalent to a cure. We have not felt called upon to take notice of various statements published in French newspapers in which opinions favourable to M. Doyen's contentions have been attributed to certain members of the Committee appointed to investigate his claims to have discovered both the cause and the cure of cancer. The profession will suspend its judgement till it has before it the report of that Committee; and, if that be favourable, it will welcome the pronouncement not as necessarily final, but as warranting a hope that a problem of the highest importance to mankind is at last on a fair way towards solution.

A like attitude of unbiassed expectancy is desirable in regard to the researches of the Buffalo investigators. They must be considered in connexion with a further report of the Harvard Cancer Commission lately issued, in which the opinion is expressed that cancer is not hereditary, and that it can be best cured by the knife. The members of the Commission were Dr. E. Nichols, Dr. F. B. Mallory, Dr. Edwin A. Locke, Dr. Charles J. White, Dr. W. H. Robey, jun., Roxbury; Dr. Tyzzer and Dr. Weis, now of New Orleans. Dr. Nichols, under whose directiun the laboratory work, which was done at Harvard Medical College and Massachusetts General Hospital, was carried out, is reported to have said :

Our work thus far has been to find the cause or origin of cancer, and we have been unable to do so, although we have exploded popular theories. When wo know what life is I think we will then know what cancer is. No more is known about its origin now than at the beginning of the Christian era. It is a supreme mystery. On present lines of investigation the cause of true cancer will never be learned. Our only hope is in some new method. No discovery has been made which offers any hope of cure of cancer whieh begins to compare with the surgeon's knife.

Ruskin says somewhere that he never thought he was getting near the truth about anything till he had contradicted himself half a dozen times. If truth is indeed evolved from contradiction, we should be coming near the elucidation of the mystery of cancer.

\section{THE EPIDEMIC OF TYPHOID FEVER IN LINCOLN.} III.

THE total number of notifications for the week ending Friday, March 3rd, was 37, showing that the epidemic has steadily decreased, the notifications of the four preceding weeks having been $284,174,116$, and 63 respectively.

The total number of cases notified since the beginning of the outbreak amounted on March 3 rd to 769 . Up to the same date 77 deaths had been recorded, showing a case-mortality of ro per cent.

The control and prevention of the "secondary cases," which continue to occur, depend upon detailed precautions, in addition to the general purification of water supply and of drains and sewers, - for example, the provision of facilities for cleansing and disinfection of dwellings and their surroundings, and of clothing, bedding, etc.; the instruction of the uninformed of all classes with regard to the risks of typhoid infection, and the ways in which those risks may be obviated; the special instruction of those engaged in nursing or attending upon the typhoid patients; the careful supervision of convalescent patients, and provision for disinfection and removal of their excreta until those excreta may reasonably be regarded as free from infectious germs.

It is difficult to ascertain to what extent these detailed precautions are being carried out; but it is satisfactory to note that the Corporation have succeeded in the difficult task of securing a free convalescent home for some 60 of the more needy class of patients, and are still engaged in seeking for further accommodation.

On February 28th Drs. Houston and MacGowan submitted their report on the methods used for the purification of the waterworks' supply, and on the results obtained. They express their belief in

the innocuous character of the water now sent into consumption on the facts that $(\mathrm{r})$ in all the ten analyses of the reservoir waters, after treatment, no B. coll have been found in as much as rooc.cm. of the water; (a) a similar result has been obtained in our later analyses of the water passing into consumption from the waterworks.

On this very important question with regard to the purification of water, Dr. Houston is well known as one of our highest authorities. The report continues :

Until a new and more satisfactory supply of water has been obtained we are of opinion that the above treatment-that is, with sodium hypochlorite-should be continued under constant supervision, and controlled by periodical analyses. ... We do not at this stage feel justified in saying that this additional precaution (boiling) should be discontinued.

Meanwhile, every effort is being made, under the skilled guidance of Mr. Hill and Mr. Whitaker, to find a safe water supply sufficient to meet the needs of the city.

ROYAL COLLEGE OF SURGEONS OF EDINBURGH.

Fourth Centenary Celebration.

Bу JонN Sмiтh, M.D., LL.D., F.R.C.S.Edin., And President, 1884.

[Written by Request.]

IT has been already intimated in the British MEDICAL JournaL that the fourth centenary of the Royal College of Surgeons of Edinburgh is proposed to be celebrated by that ancient and distinguished body during the month of July, 1905 .

Four hundred years ago the Barber Surgeons of Edinburgh resolved to petition the civic authorities of the burgh that in the interests of medical reform they should be incorporated and invested with such powers and privileges as would enable them to organize and arrange a system of teaching, examining, and certifying the professional fitness of all persons entering upon the practice of surgery within the town. The status and qualifications proposed to be made imperative on such andidates, were in this petition definitely set forth, as were also the penalties to be incurred by the infringement of such regulations; while the powers and privileges sought to be conferred upon the new incorporation were at the same time fally and explicitly detailed. The "Bill of :Supplication," as this petition was called, was presented to the Provost, Baillies and Council of the Burgh by the Barber Surgeons through their "kirkmaister," from which it may be inferred that there already existed some kind of association of the craft, although evidently without the legislative powers and the constitution they now advocated and desired.

The terms of this petition met with the unqualified approval of the authorities appealed to, and in their opinion were acknowledged to be of a reasonable and beneficial nature. They were accordingly granted, and "confirmed, ratified, and approved" by the "Seal of Cause" of the Provost, Baillies, and Council of the Burgh, July Ist, 1505, while they received the Royal Charter of King James IV in the month of March of the following year. In this way the College of Surgeons of Edinburgh must be regarded as the senior surgical corporation in the United Kingdom. During its long existence its roll of membership has been adorned with many of the most illustrious names in the medical history of Great Britain. Like all other great institutions, it has had manv difficulties to meet and overcome, but its influence and its efforts have ever been directed towards promoting the best interests and welfare of the medical profession, and it may now certainly be congratulated upon the success of many important measures which, during its honourable career, it has either supposted or achieved.

Subsequently to its original Charter, the College bas received many other Royal concessions and grants in its 
favour. In 1567 its members were exempted by Mary Queen of Scots from serving on juries, or as combatants in war, or in keeping watch and ward within the city. In 1613 its charter as conferred by. James IV was reconfirmed by James VI. In 1657 the Town Council instituted a "brotherhood" of the Apothecaries, which at a somewhat anxious crisis in its history in 1695 was annexed to the surgeons, while by a decision of the Court of Session, February, 1722, after considerable discussion and some litigation, the surgeons ceased to be connected with the barbers further than for some time subsequently keeping a record of their being licensed for that special calling. About this period also, the College was intimately associated with the development of the far-famed Edinburgh Royal Infirmary. In 1778 the College obtained an altogether new charter from George III, by which its designation became "The Royal College of Surgeons of the City of Edinburgh." According to this charter it still remained as it had been from its formation-a civic as well as a medical incorporation, and it was not till another charter was received so late as in 185 , that the government of the College was entirely separated from the Town Council's jurisdiction, at which date its name was again altered to "The Royal College of Surgeons of Edinburgh." Another addition to the grants it secured was that of the 27 th year of the reign of George III, empowering it to institute what was known as the Widows Fund, a scheme which is now in abeyance.

The original licence for practice issued by the College was a Single diploma, the examination for which embraced the subjects both of medicine and surgery. This qualification was held in high estimation, and many distinguished physicians as well as surgeons possessed no other. In 1859 however, the College of Surgeons along with the College of Physicians instituted what was called the Double qualification, which consisted of the combined licence of both colleges, conferred after a single examination. This diploma superseded the single qualification of the College of Surgeons, and continued to be conferred in its stead until 1884 , when it again gave place to still another licence which his been the only general qualification granted by these bodies since that date and now in conjunction with the Faculty of Physicians and Surgeons of Glasgow. In this way the new licence is known as the Triple qualification, under which there are granted the three diplomas of the two colleges of Edinburgh and that of the Faculty of Glasgow, conferred after a single conjoint examination.

Besides these general qualifications, other special diplomas are granted by the College. Subsequently to the passing of the Dentists Act in 1878 the College instituted its Diploma in Dental Surgery; and in conjunction with the Royal College of Physicians and the Faculty of Glasgow also established the Diploma in Public Health. For the Fellowship of the College a comprehensive and exacting examination requires to be passed previous to being admitted to the ballot for election as a Fellow.

The Royal College of Surgeons occupies as its head quarters the handsome edifice known as Surgeons' Hall, situated in Nicolson Street, a southern district of Edinburgh-the "Quartier Latin," in fact, of that ancient city. The previously existing old Chirurgeons' Hall-the birthplace of the Edinburgh Medical School-was for a long period situated in Surgeon Square, for ages a well-known medical centre of the town, and where some remnants of the ofd hall still remain. In the new building the ground floor is occupied by the large meeting room, containing the interesting collection of portraits belonging to the College, the examination and committee rooms, the library, and the lofty vestibule containing the celebrated original cast of the cadaver by John Goodsir, along with several busts. The upper floor is wholly devoted to the accommodation of the great museum.

It is proposed that the celebration of the fourth centenary of the College should take place in July, and extend over at least two days of that month. It will include a service in the old Cathedral of St. Giles, a reception and address by the President, a ceremony at which a number of honorary fellowships of the College will be conferred, a banquet given by the President and Fellows, a reception and conversazione by the Lord Provost and magistrates, and probably a garden party, with several other entertainments.

Tre Municipal Council of Paris resumed its sittings on March 8th, when it proceeded to the election of officers. The choice of a president fell this year to the Socialist group. which chose as its candidate a member of the medical profession, Dr. Brousse.

\section{METROPOLITAN CONVALESCENT HOMES ASSOCIATION.}

AN important and influential meeting to consider the establishment of a Convalescent Homes Association was held on March 2nd, under the chairmanship of Sir E. HAY CURrie, in the rooms of the Royal Medical and Chirurgical Society, 20, Hanover Square. Amongst those present were: Lord Lytton, Sir W. Ohurch, Mr. J. Tweedy, Sir T. Smith, Sir R. D. Powell, Sir D. Duckworth, Sir H. Burdett, Dr. J. K. Fowler, Dr. S. H. Habershon, Mr. T. Bryant, Lady Frederick Cavendish. and others. The conference was attended by delegates from all the chief convalescent institutions which supply charitable relief to London patients, and was convened to obtain some form of union and co-operation between the various convalescent homes. The advances in medicine and surgery necessarily entailed from time to time changes in the character of relief which can be afforded by convalescent homes, and it was considered that such changes could best be initiated and carried out through a central association in immediate touch with the hoepitals on the one hand and the homes on the other. It was further hoped that the Association would prove beneficial in centralizing and combining effort, in the exchange of administrative experience, and in promoting economy.

The proceedings commenced with the reading of letters of regret at inability to be present and expressing sympathy with the movement from Sir William Broadbent, Sir Victor Horsley, Sir Lauder Brunton, Sir Thomas Barlow, and Mr. Anthony Bowlby, C.M.G.

The Chairman said that it would be a great satisfaction to all if, when the proposed Executive Committee was appointed, they could see their way by co-ordination and co-operation to make the existing homes and institutions meet the want that existed. The very last thing that ought to be done was to go in for bricks and mortar and build new convalescent buildings. It was wrong, in his opinion, to divert money to pay for new buildings till it was perfectly clear that the existing institutions were in a position to carry on their work.

Sir William Cinurch (President of the Royal College of Physicians of London) moved the following resolution :

That the increasing needs of medicine and surgery require some alteration in the character of relief afforded by convalescent homes to the poor of London.

He said that the purpose of those attending that meeting was not to criticize but to see by what means greater good might accrue to hospital patients. Many of the patients in the present convalescent homes were not people who had been ill but persons of weak and feeble health who might very well be accommodated in homes of rest. There were about thirteen general hospitals in the metropolis with convalescent institutions of their own, or closely connected with them, but there were about seventeen that had no such homes. The reason why some change was desirable in convalescent homes was connected with the method of their management. The patients were supposed to be able to attend to themselves, and there was only one scale of diet. It would be an enormous advantage to the hospital population in London if that were not the case. Many patients would be far better off if treated in the pure air of the country, but could not be sent because they were not fit to take the same diet as people who had not been ill, such as cases after enteric fever and diseases of the stomach. Sir W. Church also deprecated the strict rule obtaining in convalescent homes that no person with an open wound could be admitted. There were a great number of those cases that required merely simple dressing, and they were the very cases that would get on quickly in a country atmosphere. He thought the proposed Committee would be able to find some method which would deal satisfactorily with these cases. He did not, however, wish it to be thought that he advocated in any way changing convalescent homes into country hospitals. Only a few nurses would be wanted who understood simple dressing, and the patients would require little attention. In regard to rest homes, he suggested that it would be better to have some organization by means of which patients for these homes could be boarded out amongst people of their own class in the various districts where it would be advisable to send them.

Mr. TwEkDY (President of the Royal College of Surgeons of England), in seconding the resolution, said that the increasing need for alteration in the character of the relief of convalescing patients was due to the improvements in recent times in medicine and surgery. Those who recollected the hospitals 